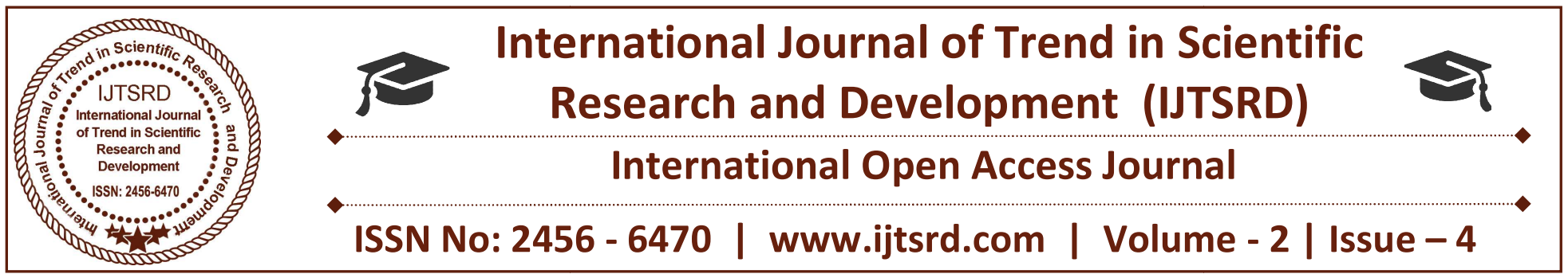

\title{
Thermal Imaging based Search Operation using Drone
}

\author{
Naveen Kumar ${ }^{1}$, Shivam Tyagi ${ }^{2}$, Vaibhav Prajapati $^{2}$, Saurabh Kumar ${ }^{2}$ \\ ${ }^{1}$ Assistant Professor \\ ${ }^{1,2}$ Department of Mechanical Engineering, ABES Engineering College, Ghaziabad, Uttar Pradesh, India
}

\begin{abstract}
In current scenario, if any person is trapped under the damaged building then the only way to identify its position is to search in the pile of concrete. This process is time consuming and chances of finding the body in short period of time are less. So to reduce the risk of life, we can use thermal sensors which can detect the position of the body with the help of energy wave radiated by it. In this paper, we will be able to detect the location of trapped body easily and risk of losing life will reduce.
\end{abstract}

Keywords: sensor, drone, human body thermal waves, surveillance

\section{Introduction:}

In any disaster if any building falls in which number of lives are stucked, then firstly it will be difficult to count the number of lives trapped under the building with their exact position. Presently the only available way to face this is to search the body in the pile of building concrete which is a time taking process and risk of losing many lives is very high. Sometimes, we feel helpless to save the lives due to lack of time available for the rescue. In this duration of time, it may be possible to save many lives if they can be detected without consuming any time.

In this paper, we will discuss about how to detect the human body with the help of thermal camera's installed in drone so that we can detect the body easily without wasting much time in search operation $[1,2,3,4]$. Drone reconnaissance empowers clandestinely assembling data about an objective as caught from a separation or height. Drone's flight capacities, little size and capacity to withstand brutal conditions mean they can frequently overview

subjects that won't not be open. When drone is flying over the searching area, it will show thermal images[6,7] of that area on the screen which will make detection easy and less time consuming.

1022

\section{$\theta$}

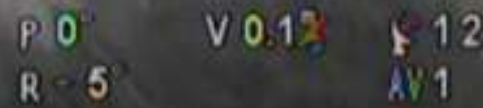

Ni1

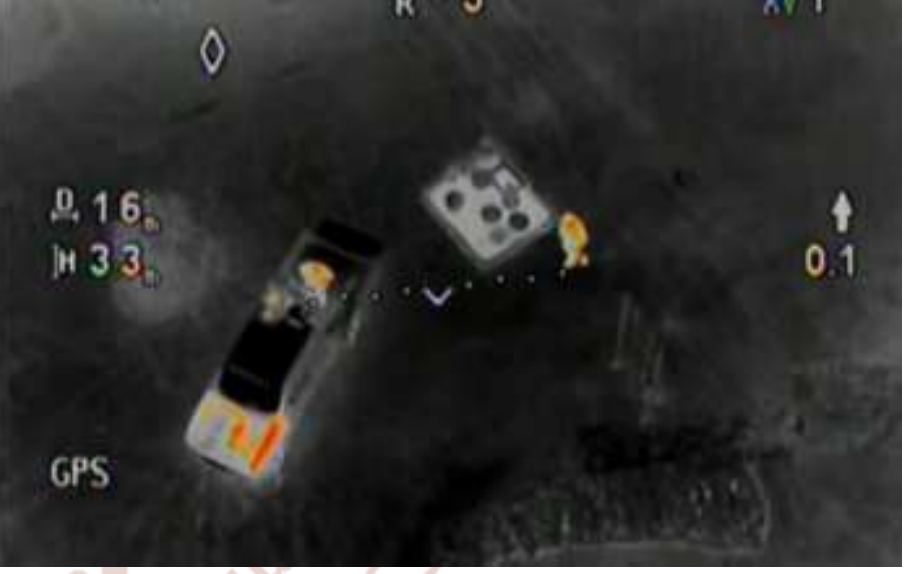

Figure1: thermal image from drone view

\section{Methodology:}

Figure 2 gives a mission flowchart. Once a wild SAR mission is asked for to the Ground Control System (GCS), the GCS administrator outlines a flight way that covers the hunt zone and sends the automaton into the air to direct the mission. Amid the flight, the on-load up picture preparing framework is intended to distinguish targets. These constant pictures and summed up GPS enable the quick safeguard to activity including guiding the casualty to sit tight for save at the momentum area and conveying crisis pharmaceutical, nourishment and water. 


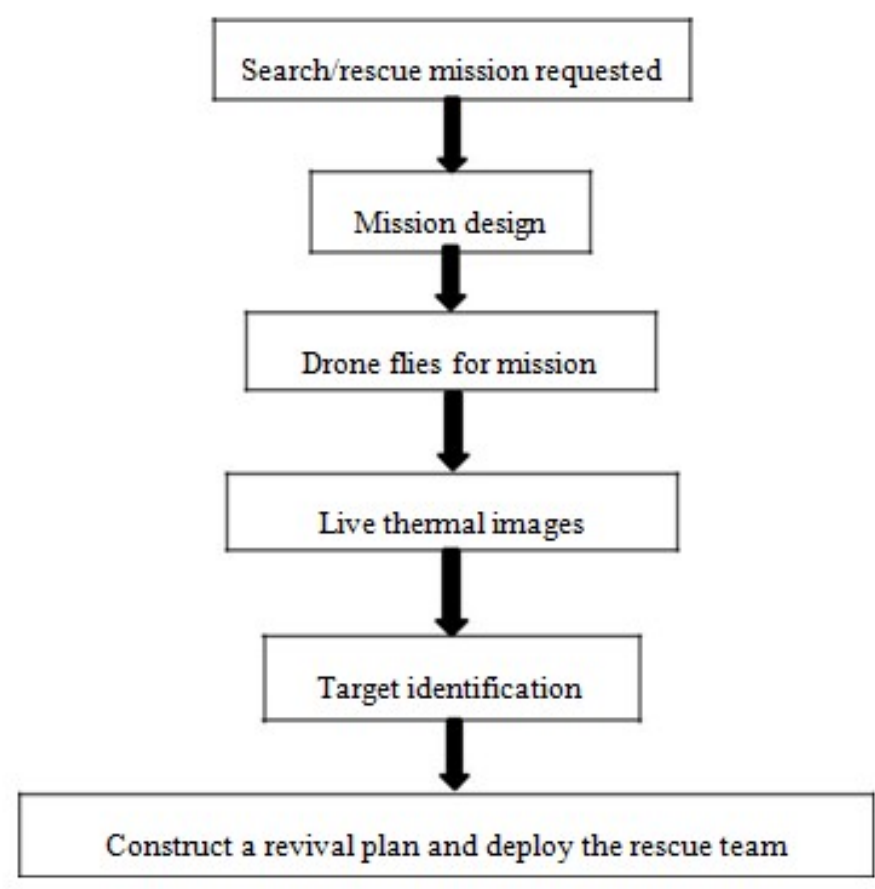

Figure 2: Methodology

\section{Components required:}

1. Drone (quadcopter):

A quadcopter is a multirotor helicopter that is lifted and impelled by four rotors. Quadcopters are named rotorcraft, rather than settled wing air ship, in light of the fact that their lift is produced by an arrangement of rotors. Quadcopters by and large utilize two sets of indistinguishable settled pitched propellers; two clockwise $(\mathrm{CW})$ and two counterclockwise $(\mathrm{CCW})$. These utilization autonomous variety of the speed of every rotor to accomplish control. By changing the speed of every rotor it is conceivable to explicitly produce a coveted aggregate push; to situate for the focal point of push both along the side and longitudinally; and to make a coveted aggregate torque, or turning power.

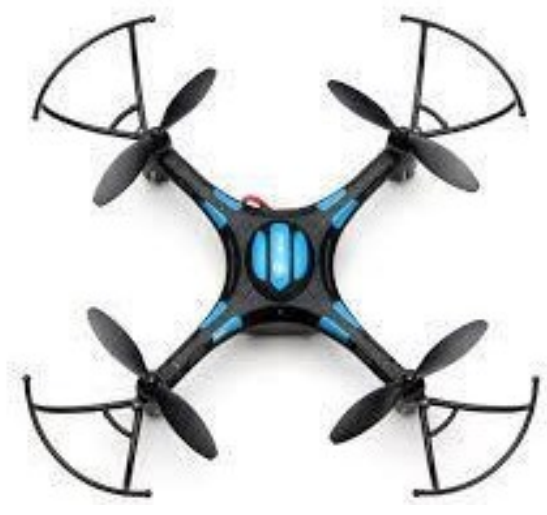

Figure 3: Drone

\section{Gimbal:}

The automaton gimbal is the turning mount, which pivots about the $\mathrm{x}, \mathrm{y}$, and $\mathrm{z}$ tomahawks to give adjustment and pointing of cameras or different sensors.

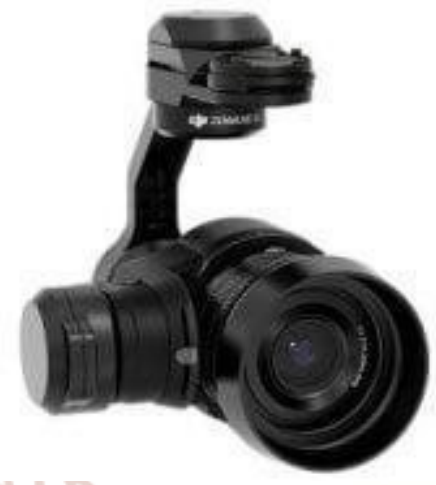

Figure 4: Gimbal

\section{Gimbal motor:}

Brushless DC engines can be utilized for coordinate drive precise situating, which require exceptionally twisted loops and devoted control hardware which have just as of late turned out to be financially accessible.

4. Gimbal controller unit:

Permits control of direct-drive brushless gimbal engines as though they were standard servo engines.

\section{Sensor:}

Sensor is mounted below the drone so that thermal image of site can be captured.

\section{Conclusion:}

In this paper, we are proposing the method to reduce the wastage of time in search operation with the help of drone mounted with thermal sensors. Thermal images received from drone will be used to identify the target body without wasting time so that rescue team can be deployed as soon as possible.

\section{References:}

1) Goodrich M.A., Morse B.S., Gerhardt D., Cooper J.L., Quigley M., Adams J.A., Humphrey C. Supporting wilderness search and rescue using a camera-equipped mini uav. J. Field Robot. 2008;25:89-110. doi: 10.1002/rob.20226. 
2) Goodrich M.A., Cooper J.L., Adams J.A., Humphrey C., Zeeman R., Buss B.G. Using a mini-uav to support wilderness search and rescue: Practices for human-robot teaming; Proceedings of the 2007 IEEE International Workshop on Safety, Security and Rescue Robotics; Rome, Italy. 27-29 September 2007.

3) Goodrich M.A., Morse B.S., Engh C., Cooper J.L., Adams J.A. Towards using unmanned aerial vehicles (UAVs) in wilderness search and rescue: Lessons from field trials. Interact. Stud. 2009;10:453-478.

4) Habib M.K., Baudoin Y. Robot-assisted risky intervention, search, rescue and environmental surveillance. Int. J. Adv. Robot. Syst. 2010;7:1-8.

5) Mikolajczyk K., Schmid C., Zisserman A. Human detection based on a probabilistic assembly of robust part detectors; European Conference on Computer Vision, Proceedings of the 8th European Conference on Computer Vision;
Prague, Czech Republic. 11-14 May 2004; Berlin/Heidelberg, Germany: Springer; pp. 69-82.

6) Rudol P., Doherty P. Human body detection and geolocalization for uav search and rescue missions using color and thermal imagery; Proceedings of the 2008 IEEE Aerospace Conference; Montana, MT, USA. 1-8 March 2008.

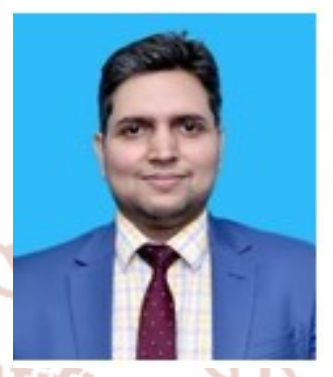

Naveen Kumar graduated in Mechanical Engineering and earned his Masters degree in Production and Industrial Engineering. In present time, he is working as Assistant Professor in Mechanical Engineering Department at ABES Engineering College, Ghaziabad, India. He has almost seven years of teaching experience and has published two research papers in international journals. 